\title{
Investigation of Properties of Thixoprocessed LM4
}

\author{
*A.V. Adedayo ${ }^{1,2}$, S.A. Ibitoye ${ }^{1}$, O.O. Oluwole ${ }^{1,3}$, K.M. Oluwasegun ${ }^{1}$ \\ ${ }^{1}$ Department of Materials Engineering, Obafemi Awolowo University, Ile-Ife, Nigeria \\ ${ }^{2}$ Department of Metallurgical Engineering, Kwara State Polytechnic, Ilorin, Nigeria \\ ${ }^{3}$ Department of Mechanical Engineering, University of Ibadan, Ibadan, Nigeria \\ *Corresponding Author: a.v.adedayo@gmail.com
}

\begin{abstract}
Thermomechanical treatment on cast Al-Si-Cu alloy (LM4) was carried out. The aim is to determine effects of degree of cold work, slurry thermal treatment and soaking time on the tensile strength, ductility, hardness and microstructure of the alloy. LM4 was prepared and cast in sand mould into rods of $\Phi 50 \mathrm{~mm}$ and $200 \mathrm{~mm}$ in length. The prepared rods were then thermally treated at $635^{\circ} \mathrm{C}$ which fall within the slurry region of the alloy. The heated samples were soaked at this temperature for various times of: 5, 10, 15 and $20 \mathrm{~min}$. A none-treated sample was also kept as control specimen. The thermally treated rods were subjected to various degrees of cold work. $10 \%, 15 \%, 20 \%, 30 \%$ degrees of cold work were used. Hardness, tensile strength and elongation of the samples were determined. The metallographic examination of the samples was also carried out. Results of mechanical property test show sensitivity to degree of cold work, thermal treatment soaking time. The microstructures of the alloy also show significant modifications as a result of thermal treatment.
\end{abstract}

Keywords: SSM, thixocasting, rheocasting

\section{INTRODUCTION}

Semi Solid Metallurgy (SSM) is a very trendy near-net-shape manufacturing process. The high level of excitement and optimism that pervades the subject is reflected by the large number of publication on the subject [1-7]. The series of conferences and workshops held on the subject also reveal the progresses made in the field of Semi Solid Metallurgy [8]. 
Semi Solid Metallurgy, also known as Semi Solid Metal Processing (SSMP) [1, 2, 8-10] is now in its fortieth year. The original experiment leading to the invention of SSM was initiated in early 1971 by David Spencer, Merton Flemings and Co-workers. In the experiment, the fundamental principle behind semi solid metallurgy was discovered to involve fragmentation of secondary dendrite arm during solidification.Semi Solid processing is typically classified into two major categories: Rheocasting and Thixocasting. Rheocasting refers to any process that modifies liquid alloy into semi solid slurry that is then directly formed into a part. Thixocasting refers to any process that starts with a specially prepared alloy that is reheated from ambient to the desired semi solid forming temperature prior to forming.

Numerous process advantages are derived from the forming of alloy by SSM, however, the most widely cited benefits of SSM usually refers to the final part quality, complexity and properties [7]. The influence of SSM on the direction of changes of alloy properties is not universally positive and should be evaluated for individual alloy chemistry [1,9]. Understanding the difference between the integrity and microstructure is not only important for the proper selection of the processing parameters to achieve the maximum with existing alloys, but also for the development of new alloys designed for semi solid techniques.

In this present study, the metallurgical properties of thermomechanically treated LM4 alloy are presented. Generally, LM4 alloy is suitable for most general engineering purposes; however, the effects of thermal treatment on the alloy properties will provide useful design information for engineering applications.

\section{MATERIALS AND EXPERIMENTAL PROCEDURE}

The materials used to prepare the LM4 metallurgy alloy are aluminum-silicon master alloy, aluminum - copper master alloy and aluminum scrap. Four kilograms (4.5 kg) of Al-Si master alloy, $3.5 \mathrm{~kg}$ of $\mathrm{Al}-\mathrm{Cu}$ master alloy were melted at a temperature of $720^{\circ} \mathrm{C}$ with $6 \mathrm{~kg}$ of aluminum scrap in a lift-out electric crucible furnace (see Table 1). A total of $14 \mathrm{~kg}$ of LM4 was produced by casting into cylindrical rods of $50 \mathrm{~mm}$ in diameter and $200 \mathrm{~mm}$ in length. The quantitative chemical analysis of the essential elements in the produced LM4 was carried out using Atomic Absorption Spectrophotometer (AAS) while the silicon content was determined by gravimetric analysis. The result of the chemical analysis is presented in Table 2. The result showed that the percentage of the major alloying elements compared well with chemical composition of standard LM4 alloy [11, 12]. 
Table 1. Proportion of materials charged for the production of LM4 alloy.

\begin{tabular}{|l|l|l|}
\hline Material & Weight & \multicolumn{2}{|l|}{} \\
\hline & $\mathrm{Kg}$ & 32 \\
\hline Al-Si & 4.5 & 25 \\
\hline Al-Cu & 3.5 & 43 \\
\hline Al scrap & 6.0 & 100 \\
\hline Total & 14 & \\
\hline
\end{tabular}

Table 2: Chemical composition of the prepared alloy by AAS and gravimetric analysis

\begin{tabular}{|l|l|}
\hline Elements & Average (wt \%) \\
\hline $\mathrm{Si}$ & 5.8010 \\
\hline $\mathrm{Cu}$ & 3.8320 \\
\hline $\mathrm{Mg}$ & 0.4116 \\
\hline $\mathrm{Fe}$ & 0.2320 \\
\hline $\mathrm{Mn}$ & 0.0232 \\
\hline $\mathrm{Al}$ & Rest \\
\hline
\end{tabular}

The prepared rods were thermally treated at a temperature of $635^{\circ} \mathrm{C}$ which falls within the slurry temperature zone of the alloy. The heated samples were soaked at this temperature for various times of: 5, 10, 15, and 20 min, after which they were removed from the furnace and quenched in water. The thermally treated rods were subjected to various degrees of cold work. $10 \%, 15 \%$, $20 \%, 30 \%$ degrees of cold work were used. There was also a none-treated sample. This serves as control specimen. Hardness, tensile strength and elongation of the samples were determined. The metallographic examination of the samples was also carried out. The etched specimens were observed on the Olympus metallurgical microscope with a minisee optical viewing system connected to the USB port of a computer in the Department of Materials Science and Engineering of the Obafemi Awolowo University. Micro examination was carried out at a higher magnification of 200X and images captured for metallographic analysis.

\section{RESULT AND DISCUSSION}

Figures 1, 2 and 3 show the variation of some of the mechanical properties of the treated alloy with deformation and time at $635^{\circ} \mathrm{C}$. Figure 1 show the effects of deformation and soaking time on the tensile strength of the alloy. Strength increased with deformation, while strength decreased with soaking time. However, some critical points are observed. For soaking time of 0 and 5 min., there was increased strength for $0 \%$ deformation till $10 \%$ where it became steady 
until 15\% where it gained rapid increment again. However, for soaking times: 10 and 15 mins., the increment was generally increasing however with varying vigor at different degrees of deformation. The primary species responsible for strengthening are dislocations. Dislocations interact with each other by generating stress fields in the material. The interaction between the stress fields of dislocations can impede dislocation motion by repulsive or attractive interactions. Additionally, if two dislocations cross, dislocation line entanglement occurs, causing the formation of a jog which opposes dislocation motion [13, 14]. These entanglements and jogs act as pinning points, which oppose dislocation motion. As both of these processes are more likely to occur when more dislocations are present, there is a correlation between dislocation density and tensile strength of an alloy. In most alloy systems, alloying above a certain concentration will cause the precipitation of a second phase. A second phase can also be created by mechanical or thermal treatments [13] or the synergistic interaction of both mechanical and thermal treatments.

Generally, during slurry thermal treatment, a sort of equilibra is established within the system. There is a balance between the solid and the liquid phases of the alloy present. This leads to solute redistribution between the solid and the liquid and thus varied compositions of the solid and the liquid. The enrichment of a liquid alloy in certain chemical elements leads to increased precipitation of phases and modifications in their distribution pattern. In some cases, the phases not present during complete liquid casting may be formed [9]. The particles that compose the second phase precipitates act as pinning points in a similar manner to solutes in solution strengthening, though the particles are not necessarily single atoms. The microstructures of the alloy reveal various precipitates of various sizes. The dislocations in a material can interact with the precipitate atoms in one of two ways. If the precipitate atoms are small, the dislocations would cut through them. As a result, new surfaces of the particle would get exposed to the matrix, and the particle/matrix interfacial energy would increase. Adedayo [15-17] showed a relationship between material strength, surface energy and interfacial energy. In general, the nature (brittle or ductile) and location (inside the primary phase or at the grain boundary) of the precipitates have significant effects on the strength of the materials [9]. For the alloy, the range of possible precipitates in the alloy is a bit large and consists of: $\mathrm{CuAl}_{2}, \mathrm{CuAl}_{2} \mathrm{Mg}, \mathrm{Mg}_{2} \mathrm{Si}$, AlMnFeSi, $\mathrm{MgZn}_{2}, \mathrm{Al}_{3} \mathrm{Ti}, \mathrm{Mg}_{2} \mathrm{Al}_{3}, \mathrm{Al}_{5} \mathrm{FeSi}$ [18]. The exact manner in which these interact is not clearly understood since they interact in a highly complex manner [18].

Figure 2 shows the effects of deformation and soaking time on the hardness of the alloy. Hardness increased with deformation, while it decreased with soaking time. Critical points on the hardness graph occurred at soaking times of 0,3 and 10 mins. The reason for the observation may be due to the same factors as explained for tensile strength. Figure 3 shows the effect of deformation and soaking time on the elongation of the alloy. Generally, elongation increased with increased soaking time where as elongation decreased with deformation. 


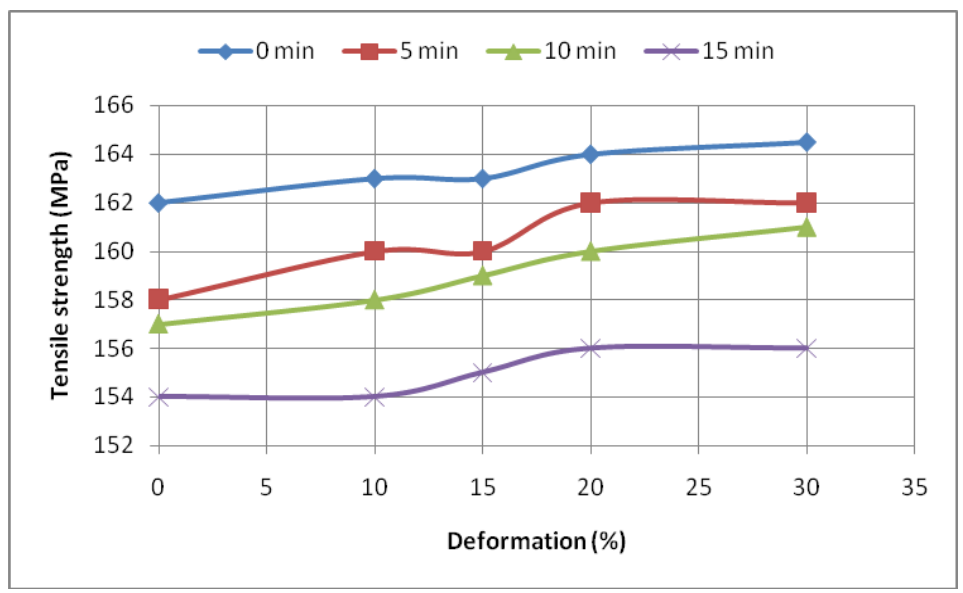

Figure 1: Variation of tensile strength with percentage deformation at $635^{\circ} \mathrm{C}$ at different soaking time

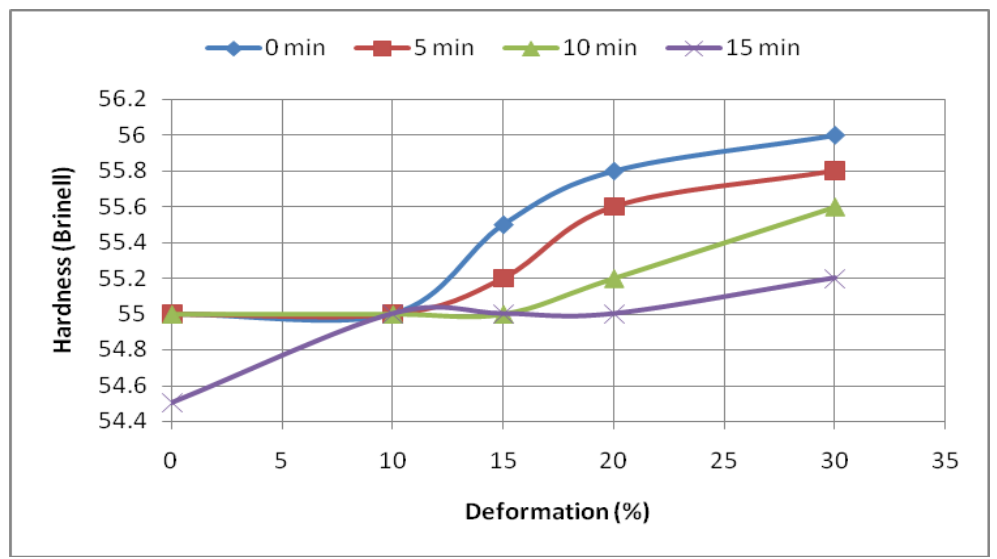

Figure 2: Variation of Hardness with percentage deformation at $635^{\circ} \mathrm{C}$ at different soaking time

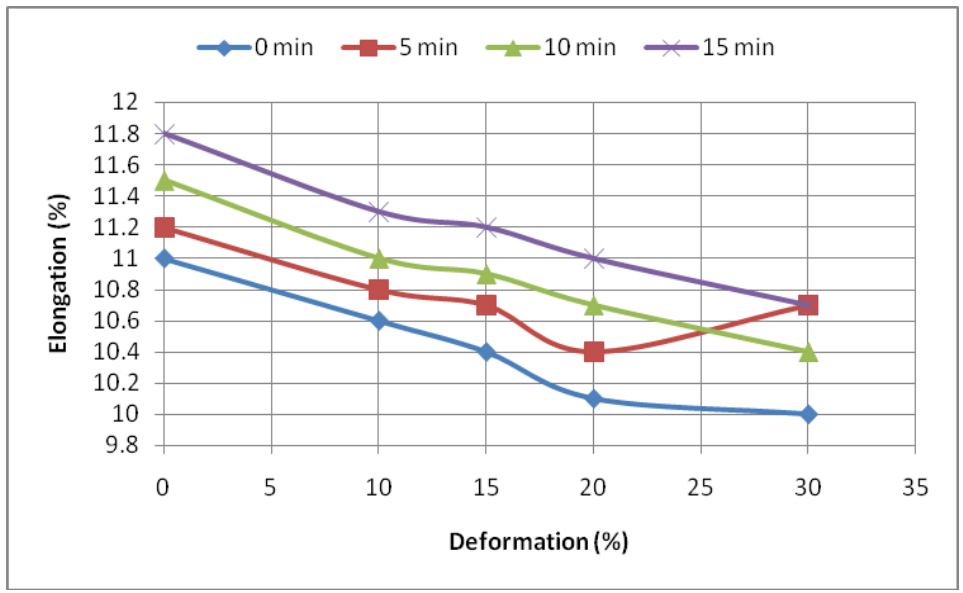

Figure 3: Variation of elongation with percentage deformation at $635^{\circ} \mathrm{C}$ at different soaking time 
Figures 4, 5 and 6 show the microstructures of the alloy. Figure 6 shows the microstructure of the untreated LM4 alloy. The proportion of acicular silicon seen in the micrograph is high relative to microstructure of the thermally treated alloys. This may be attributed to changes in morphological characteristics of the Si phase due to thermal treatment [18]. Primary aluminum phase and eutectic $(\mathrm{Al} / \mathrm{Si})$ are seen in Fig 4. The morphology of the primary aluminum phase appears somewhat globularized. $\mathrm{CuAl}_{2}$ particles are seen inside the primary aluminum phase (Fig. 4b and C). Figure 5a shows strained aluminum phase, which evidenced the effect of deformation. Figure $5 b$ reveals that some phases are actually dissolving at this thermal treatment temperature. In Fig. $5 \mathrm{c}, \mathrm{Al}_{5} \mathrm{FeSi}$ precipitate is found sandwiched in between the boundaries of the primary phase. The fractured nature of the precipitate may suggest the brittle nature of this compound.

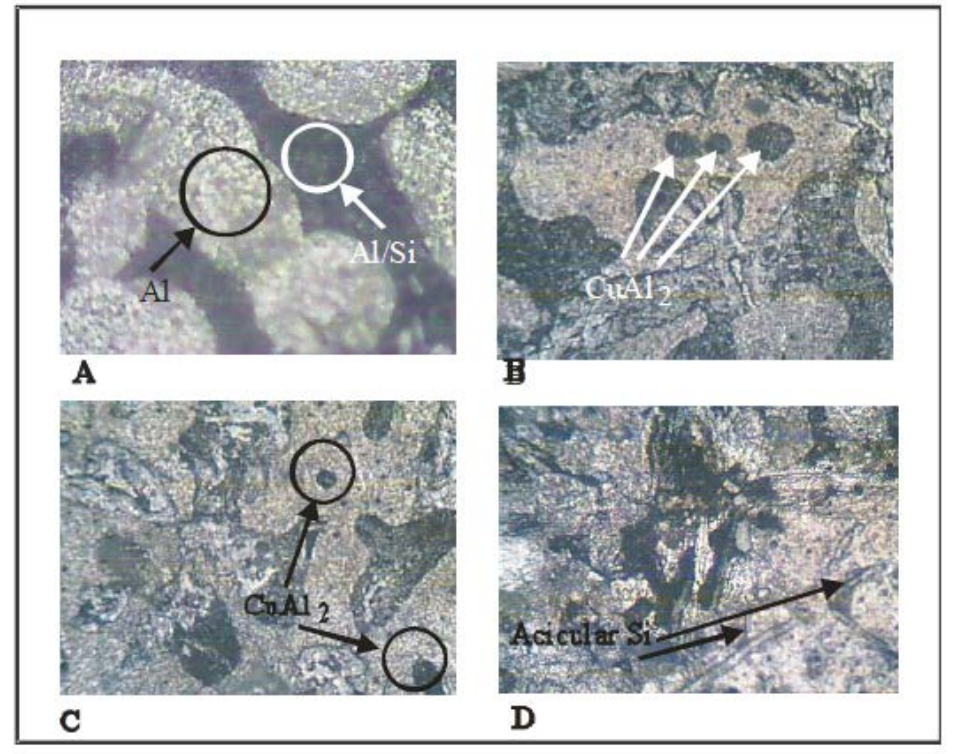

Figure 4: Microstructure of thermally treated LM4 alloy at $635^{\circ} \mathrm{C}$ and $0 \%$ deformation (A) for soaking time of 15 mins. (B) 10 mins. (C) 5 mins. (C) 0 mins. 


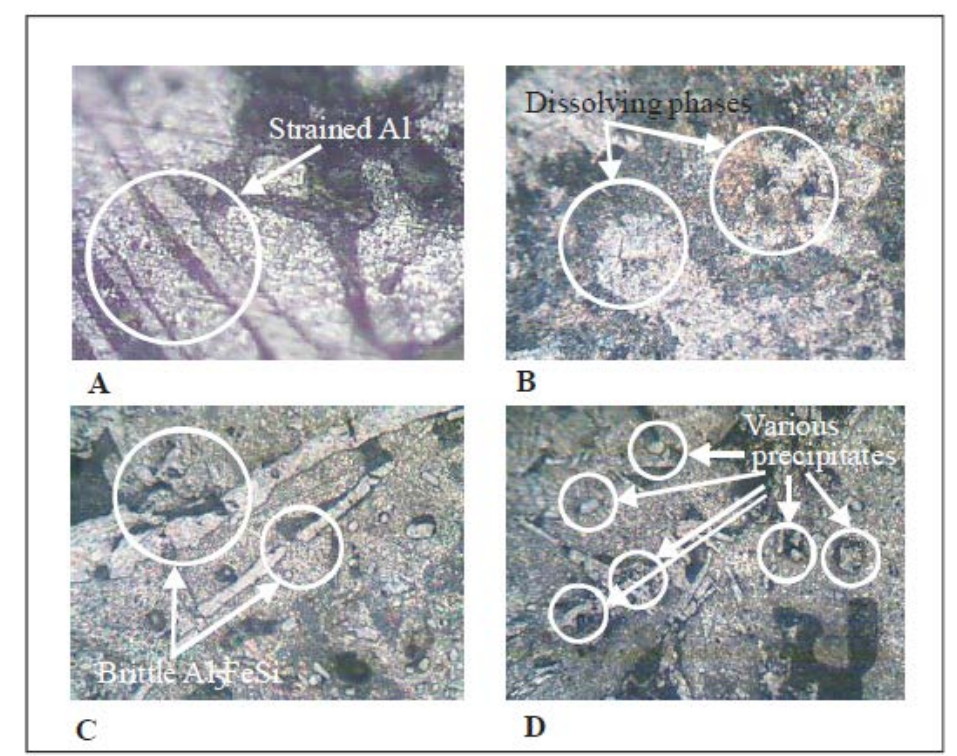

Figure 5: Microstructure of thermally treated LM4 alloy at $635^{\circ} \mathrm{C}$ and $15 \%$ deformation

(A) for soaking time of 15 mins. (B) 10 mins. (C) 5 mins. (C) 0 mins.

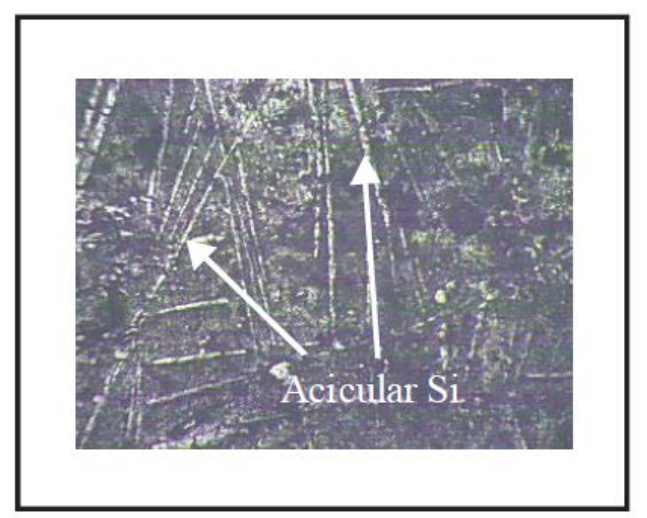

Figure 6: Microstructure of untreated LM4 alloy

\section{CONCLUSION}

Aluminum-Silicon-Copper alloy (LM4) has been produced and cold worked. The percentage of the major alloying elements in the alloy compared well with chemical composition of standard LM4 alloy. There was increase in the tensile strength of the alloy with increase in degree of. This is because of increased dislocation density with increased deformation. The increased strength is as well as a result of formation of jogs due to crossing of dislocation lines. Generally, cold deformations lead to increased strength. The hardness values reduce with soaking time, however, ductility of the alloy increased with soaking time. Observed microstructures also show significant changes in phases present due to thermomechanical treatment. 


\section{REFERENCES}

[1] Adedayo, A.V. 2011 Development processes of globular microstructure, Journal of Minerals, Materials Characterization and Engineering, Vol.10, No. 7, pp 651-659

[2] Adedayo, A.V. 2011 Influence of furnace design on semi solid microstructure, Pacific Journal of Science and Technology, Vol. 12, No. 1, pp 76 -79

[3] Oblak, J.M.; Rand, W.H. 1976 Solid-liquid phase characterization of several rheocast high performance alloys, Metallurgical Transaction B, vol.7 pp 699 -703

[4] Reisi, M. Niroumand, B. 2008 Effects of stiring parameters on rheocast structure, Journal of Alloys and Compounds, Vol 32, No. 1, pp 41-47

[5] Margarido, M.; Robert, M.H. 2003 The production of alloys with rheocast structure. Journal of Brazilian Society for Mechanical Sciences and Engineering, Vol 25, No. 2, pp 207-214

[6] Paes, M. Santos, E.G. Zoqui, E.J. 2006 Obtention rheocast structure for $\mathrm{Al} \mathrm{Cu}$ alloys, Journal of Achievements in Materials and Manufacturing Engineering, Vol. 19, No. 2 pp 2126

[7] Yurko, J.A.; Martinez, R.A.; Flemings, M.C. 2003 Commercial development of the semi solid rheocasting (SSR) process, Metallurgical Science and Technology, Vol. 21, No 3. pp $10-15$

[8] Flemings, M.C. 2000 Semi solid forming: the process and the path forward. Metallurgical Science and Technology, Vol. 18, No 2., pp.3-4

[9] Czerwinski, F. 2008 The basics of modern SSMP, Journal of the Minerals, Metals and Materials Society, Volume 60, Number 11, pp. 82-86

[10] Browne, A.J.; Hussey, M.J.; Carr, A.J. Bradazon, D. 2003 Direct thermal method: new process for development of globular alloy microstructure; International Journal of Cast Metals Research, Vol.16, No 4, pp 418-426.

[11] Chama, C.C. 1998 Journal of Materials Science Letters, Vol.17, No.21, pp1857

[12] British Standard 1988: http://www.britishstandard/BS 1490:1988/

[13] Mittal, R. 2009 Strengthening mechanism of metals physical metallurgy, metallurgy \& materials engineering, National Institute of Technology, Rourkela, Roll No: 10604038, pp 56

[14] Callister, W.J. 1985 Materials science and engineering, an introduction. John Wiley \& Sons, NY pp 717

[15] Adedayo, A.V. 2010 Effects of addition of iron filings to green moulding sand on the microstructure of grey iron, Journal of the Brazilian Society for Mechanical Sciences and Engineering, Vol. 32, No 2, pp 171-175

[16] Adedayo, A.V. 2009 Effects of Iron Filings on the Properties of Green Moulding Sand, Proceedings of $2^{\text {nd }}$ National Conference of Institute of Technology, Kwara State Polytechnic, Ilorin, Vol. 2, No 1, pp 45-49 
[17] Adedayo, A.V.; Adesina, S.A.; Alagbe, M.; Ekpenyong, J.E. 2008 Adaptation of Asa-Dam River Side Sand for Engineering Use (Paper I), Proceedings of $1^{\text {st }}$ National Conference of Institute of Technology, Kwara Sate Polytechnic, Ilorin, Vol 1, No 1, pp 186-190

[18] Liu, Z.K.; Hoglund, L.; Jonsson, B.; Agren, J. 1991 An experimental and theorectical study of cementite dissolution. Metal Transactions A. 22A pp $1745-1752$ 